\title{
Preclinical study analysis of massive magnesium alloy graft for calcaneal fractures
}

\author{
ŞERBAN DRAGOSLOVEANU ${ }^{1}$, DRAGOŞ CORNELIU COTOR ${ }^{1}$, CHRISTIANA D.M. DRAGOSLOVEANU ${ }^{2}$, \\ CĂTĂLIN STOIAN ${ }^{1}$ and CRISTIAN IOAN STOICA ${ }^{1}$
}

\author{
Departments of ${ }^{1}$ Orthopedics and ${ }^{2}$ Ophthalmology, 'Carol Davila' University of Medicine and Pharmacy, \\ 050474 Bucharest, Romania
}

Received January 22, 2021; Accepted February 22, 2021

DOI: $10.3892 /$ etm.2021.10163

\begin{abstract}
The highly comminuted calcaneal fractures represent a challenge for surgeons and require bone grafts for a good clinical outcome. Postoperative results are generally associated with increased morbidity and long periods of inactivity. The biomedical community promotes the use of artificial materials for grafts in order to achieve improved results. In an era when cosmetic concerns as well as the satisfaction of patients are mandatory and the use of autologous bone grafts is not without complications, an artificial replacement appears to be a favorable option. Synthetic bone grafts are known to fail under stress shield or are associated with systemic side effects. The purpose of the present study was to investigate and determine an already commercially available magnesium $(\mathrm{Mg})$ alloy whose design is most suitable for long-term use. The mechanical properties of $\mathrm{Mg} 1 \mathrm{Ca}$ and MgYREZr compared with normal cortical and cancellous bone were assessed. Another discussed aspect was the influence of the alloy in the graft fixation. The results revealed that $\mathrm{Mg} 1 \mathrm{Ca}$ and MgYREZr alloys had a low tensile strength of 75 and $250 \mathrm{MPa}$, respectively. For this reason, it was surmised that MgYREZr alloy could be an optimal choice with favorable corrosion resistance. Since calcaneal fractures are prone to skin necrosis and septic complications, the need for antibacterial procedures and antibiotic prophylaxis is highlighted. Thus, an in vivo attempt was also made to identify the relationship between $\mathrm{Mg}$ alloy products and bacterial load. However, the most important feature of the present study was the creation of a 3D model grafting, with an anti-sliding design, which can be potentially used with the preferred $\mathrm{Mg}$ alloy in this type of fractures. In conclusion, artificial materials are the future in medicine, replacing the body-limiting capabilities of grafts.
\end{abstract}

Correspondence to: Dr Christiana D.M. Dragosloveanu, Department of Ophthalmology, 'Carol Davila' University of Medicine and Pharmacy, 8 Eroii Sanitari Blvd., 050474 Bucharest, Romania E-mail: christianacelea@gmail.com

Key words: calcaneus, grafts, alloys, fractures, bone
They are safe and incur less comorbidities. This method could pave the way for reducing patient discomfort and increasing patient satisfaction. Although further testing is required, this research represents a great starting point for calcaneal fractures.

\section{Introduction}

Calcaneal fractures constitute approximately $2 \%$ of all fractures presenting to the emergency room. Most of them are highly comminuted and involve the posterior subtalar joint (1-4). The optimal treatment remains controversial, with conservative and surgical procedures still in use to date (5-7).

The preferred method of the present research group is surgical reduction with the addition of an autologous bone graft from the iliac crest. However, the high morbidity of this type of fracture is well known; most patients returning to work after a lengthy period, while some are unable to work even after one year. This fact produces physical and psychological disabilities for the patient, as well as increased costs to society (8-10).

Bone healing is a biological and physiological process controlled by biochemical, hormonal and mechanical factors. The bone is a continuous evolving entity through remodeling. Bone deposition and resorption is dependent on the blood supply, the cells that promote healing and the stability of the fixation, in case of fractures (11).

Autologous bone grafts were the first choice for numerous years. In theory, they have the characteristics required for bone healing and integration. However, the resources for bone grafts are limited, and second interventions increase residual pain for the patient (12-14).

In addition, due to the fact that bone grafting from the iliac crest is a painful limited procedure with complications ranging from nerve injury, infection, persistent pain to cosmetic deformity, a safe and solid alternative was investigated (15).

In recent years, new materials have been developed to replace natural bone. The widely used products were composed of calcium phosphate ceramics and other biosynthetic composites. In clinical trials, these types of grafts were revealed to be too weak and with limited osteoinduction (16-20).

The calcaneus fracture occurs in one of the few places in the human body where the stress shielding is limited at low 
levels. Moreover, it requires at least 3 months to heal properly, thus a slow resorption graft is required. All these characteristics promote the use of magnesium $(\mathrm{Mg})$ as a grafting option.

$\mathrm{Mg}$ has acceptable mechanical properties and it is one of the most important elements, stored in bones and essential in metabolic processes. Daily doses of $\mathrm{Mg}$ are provided continuously in regular food, in a sufficient amount that can stimulate bone cell growth and can improve the healing time of the bone. $\mathrm{Mg}$ is eliminated from the body in the presence of chlorine throughout the kidneys $(21,22)$.

Since massive $\mathrm{Mg}$ alloy grafts are not commonly used, the calcaneus is in our opinion a perfect site for a structural graft in a preclinical study. An anticipated successful result will allow us to preserve a markedly favorable graft donor site for more life threatening pathologies, including malignancies, and to reduce morbidity of the lower foot. In the future, this type of synthetic graft can be used for an increasing number of different pathologies.

The data in specialty literature is vast, thus, the most important $\mathrm{Mg}$ alloys are considered and reviewed for their properties and a direct clinical future approach is focused on by finding the appropriate design for the need of patients in this preclinical study.

\section{Materials and methods}

From a therapeutic point of view, calcaneal fractures represent a challenge. Most of the highly comminuted injuries require bone grafts to restore Bohler's angle. This variable represents the degree of inclination of the articular surfaces of the calcaneus. A lateral approach is required to access the smashed bone. After open reduction, a large 'missing' bone is found. At this level, a graft is generally used to restore and hold the height of the calcaneus and to correct varus deviation (23). The need for using a plate is frequent, fixing it with screws. This is, in our opinion, a perfect place for the usage of a synthetic graft. There is no major blood supply and the artificial metal graft does not come in contact with the steel plate, thus avoiding the risk of metallosis. The graft is protected and is held in place by a proposed design and hidden behind the lateral wall of the calcaneus. This design for the grafts, presented in the following section, is reproducible and can be used in this form and dimension to all Sanders 3 and 4 of the calcaneal fractures (Sanders classification) (Fig. 1) (24).

A CT scan with 3D reconstruction is absolutely necessary in evaluating the degree of comminution and assessing the decision to use a graft (Figs. 2-4). Thus, using these CT scans and measurements, and taking into consideration that most patients with comminuted calcaneal fractures are males, men between 30 to 60 years old and non-smokers, should be selected as the perfect candidates, to prevent skin necrosis, for the next, clinical phase of this study.

$\mathrm{Mg}$ alone has a high corrosion rate (25-30), thus in theory, it could not be used in orthopedics. Nevertheless, alloys have markedly improved characteristics including biodegradation, resistance to fatigue, ductility or strength being required as to be fully used in vivo.

In addition, $\mathrm{Mg}$ structures are potentially compatible to the human body because they are osteoconductive and biodegradable. The mechanical properties are similar to that of bones and the most important aspect is the capacity to stimulate the formation of new bone. However, the rapid degradation of this material, faster than bone healing and its formation, can lead to gas cavities, osteolysis and poor clinical results (25). Therefore, the appropriate type of $\mathrm{Mg}$ alloy had to theoretically be identified for our application and the optimal surface appearance of the design had to be decided. Using CT reconstruction, multiple angle $\mathrm{x}$-rays and our surgical experience, a 3D model similar to the iliac graft was developed in Windows 3D Viewer (Microsoft Corporation).

Previous research, in vitro, which suggested the appearance of red blood cell lysis and decreased survival of mesenchymal stromal cells, when using some Mg alloys, was considered (26), because of the tendency for tissue damage.

An attempt was also made to identify the relationship between $\mathrm{Mg}$ alloy products and bacterial load, since calcaneal fractures are prone to skin necrosis and septic complications.

\section{Results}

In the first stage of finding the appropriate alloy, the already commercially available products were identified and the data from literature was used to include them in further tests. After a close review of international prestigious publications $(21,22,25-45)$, the mechanical properties of $\mathrm{Mg} 1 \mathrm{Ca}$ and MgYREZr were selected and compared to normal cortical and cancellous bone. For references, Ti6Al4V and a markedly close to pure form of $\mathrm{Mg}$ were also assessed. Results are presented in the Table I.

Clearly, from a mechanical point of view, the synthetic graft needs to be as strong as the bone, in order to maintain the correction of the Bohler's angle to a normal range of $20^{\circ}$ to $40^{\circ}$.

The fixation of the graft is not necessary because it will be covered and kept in place by the superior calcaneus fragments and the lateral wall. A plate is required to stabilize the fragments. Since the construction of an $\mathrm{Mg}$ alloy plate is beyond our capabilities at the moment, but may be attempted in a future study, a 3D render with the design is presented in Fig. 5.

Due to the corrosion issue, a selenium-containing coating using micro-arc oxidation was selected. Data from literature clearly indicated that improved corrosion resistance was achieved in this manner (27). In theory, a minimum of a 3 -month period of implant and reduction stability is required until the external shell of the calcaneus is healed. After this period, the full strength of the alloy graft is not required anymore. Tensile strength is the main reason why MgYREZr was selected, since $\mathrm{Mg} 1 \mathrm{Ca}$ has a tensile strength as low as $75 \mathrm{MPa}$.

In addition, a small $\mathrm{Mg}$ alloy graft implanted in a female mouse ( 4 months old; weight, $31 \mathrm{~g}$; provided by the Experimental Medicine Center of the Faculty of Veterinary Medicine of Bucharest), that was already infected with Pseudomonas for antibiotic testing, was also assessed. During the experiment the mouse was maintained in a cage specially designed for this type of species. The cage was placed in a controlled environment with a 10-h light/14-h dark cycle, a temperature between $18-22^{\circ} \mathrm{C}$ and $40-50 \%$ humidity. Food and water were available ad libitum. The use of the animal was approved by the Ethics Committee of the Faculty of 


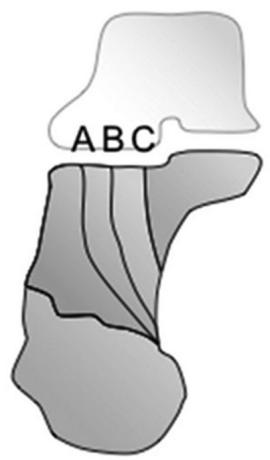

Type I

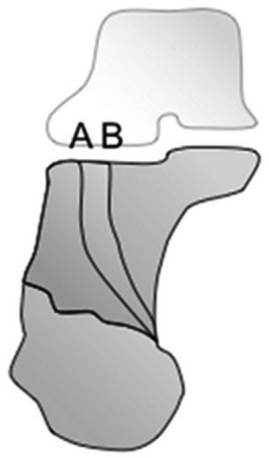

Type IIIAB

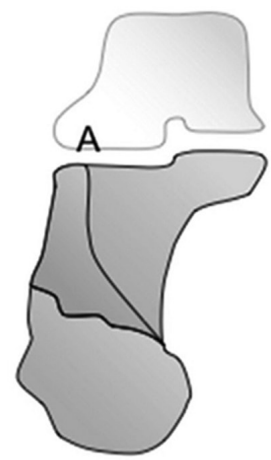

Type IIA

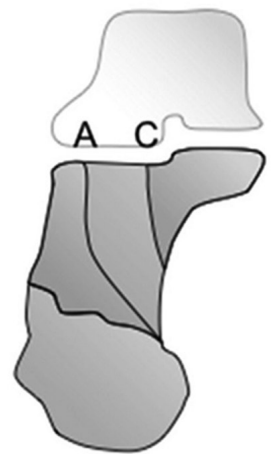

Type IIIAC

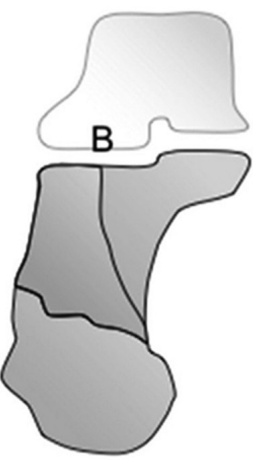

Type IIB

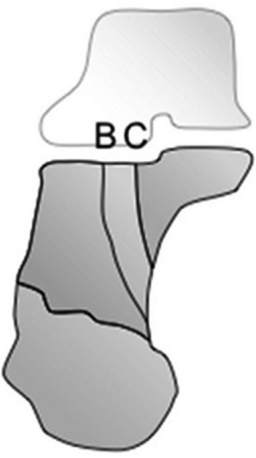

Type IIIBC

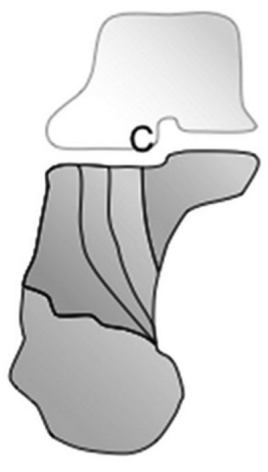

Type IIC

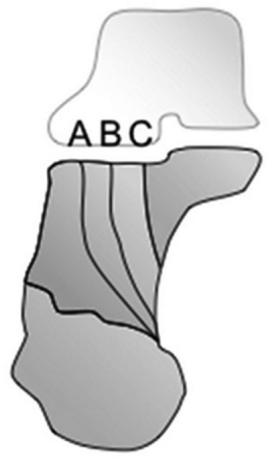

Type IV

Figure 1. Sander's classification. The number (I-IV) representing the number of intraarticular fragments and the letter (A, B, C) indicating the location of the fracture or fractures: Type I fractures are non-displaced or with $<2 \mathrm{~mm}$ articular displacement; type II fractures are displaced 2-part fractures of the posterior facet with three principal subtypes; type III fractures are displaced 3-part fractures with an associated central depression with subtypes based on the location of the fracture lines extending into the posterior facet; type IV fractures are comminuted intra-articular fractures of 4 or more parts, with 3 or more fracture lines extending to the joint and often with significant displacement.

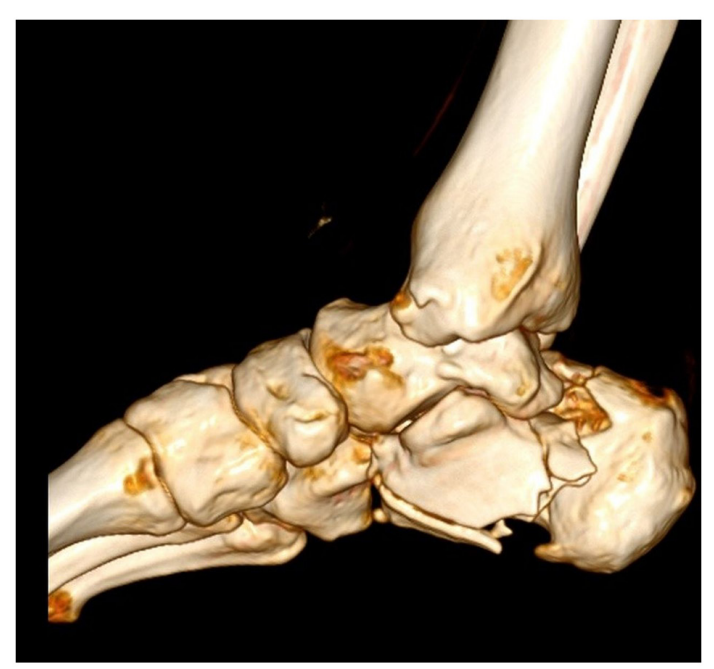

Figure 2. Lateral view of the disrupted lateral wall of the calcaneus (CT 3D reconstruction).

Veterinary Medicine of Bucharest (Bucharest, Romania). No changes in response to the antibiotics were observed, however this test was not sufficient in our opinion. Considering data from literature, caution should be taken when affirming that $\mathrm{Mg}$ alloys do not influence the antibacterial response of the biological matter (28). Since calcaneal fractures are prone to infections, the need for extra antibacterial procedures and antibiotic prophylaxis is highlighted.

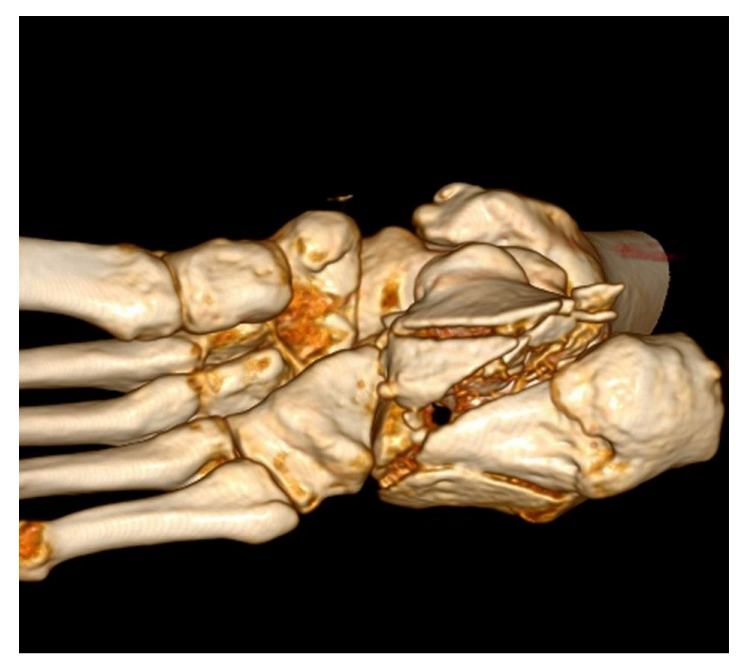

Figure 3. Inferior view of the heavily displaced lateral and medial calcaneus walls (CT 3D reconstruction).

\section{Discussion}

AZ alloys have been recently tested, especially AZ31 (Mg3Al1Zn) and AZ91 (Mg9Al1Zn), in vitro and in vivo. Both release large quantities of hydrogen on biodegradation in organic matter, increasing the $\mathrm{pH}$ and $\mathrm{Mg}$ concentration (29-32). In a small study, Witte et al determined that a Ca phosphate coating could stimulate bone formation around the graft and decrease absorption (33). 


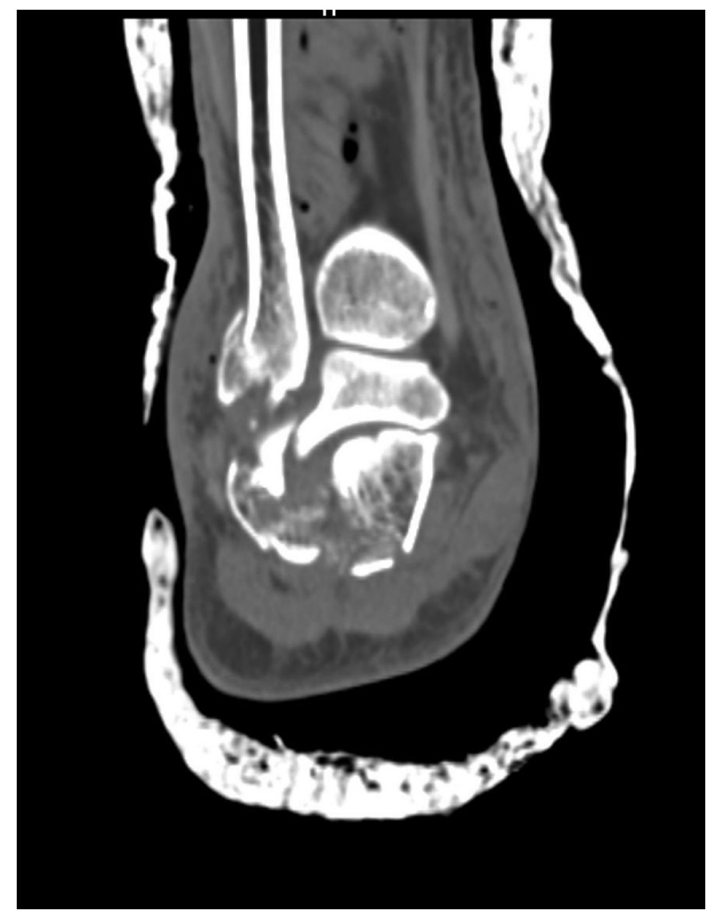

Figure 4. Axial view of the comminuted fracture (CT scan, Sander's IV).

Magnesium alloys containing rare earth elements have excellent corrosion resistance due to the formation of an oxide film (rare earth oxide film) in a 'humid' environment. WE54 (4.85 Yttrium, 1.58 Neodymium, 0.28 Zirconium, 0.08 Cerium, 0.13 Gadolinium, 0.16 Erbium and $\mathrm{Mg}$ balanced) has an improved rate of degradation in vitro than $\mathrm{Mg}$ alone if heat treatment is applied. WE43 (4.16 Yttrium, 3.80 RE, 0.36 Zirconium, 0.20 Zinc, and 0.13 Manganese) has good biocompatibility, but it increases aluminum ions in the brain, increasing the risk of Alzheimer's disease. Rare-earth elements are associated with severe hepatotoxicity $(34,35)$.

ZK40 (Mg4Zn0.5Zr) and ZK60 (Mg6Zn0.5Zr) have excellent biocompatibility and small doses of daily zinc are safe for humans, thus, Mg-Zinc alloys are better than alloys that contain aluminum. However, these materials have high rates of degradation and are not candidates for orthopedic use $(36,37)$.

Medical Mg alloys, used before in orthopedic surgeries include calcium, strontium, zinc or a combination of rare-earth elements. Alloys containing $\mathrm{Ca}$ as a grain-refining agent, and strontium (similar proprieties to calcium) are used to increase the compatibility with the human bone combined with low toxicity (38). Strontium alloys are known to be the slowest in degrading. In data published, Zhao et al (39) concluded that $\mathrm{Mg} 2 \mathrm{Sr}$ has the highest corrosion resistance with high tensile strength and good compatibility (40).

Zinc is present in the human body, it has almost no toxicity and it can be used to strengthen the $\mathrm{Mg}$ alloy through solid solution hardening. Therefore, biocompatibility is excellent (41).

Some elements in the $\mathrm{Mg}$ alloy implants form second-phase particles which can precipitate in grains, conferring better mechanical properties by strengthening the material (42-44).

When selecting $\mathrm{Mg}$ alloy implants as bone grafts, the stability and strength of second phases and the $\mathrm{Mg}$ matrix

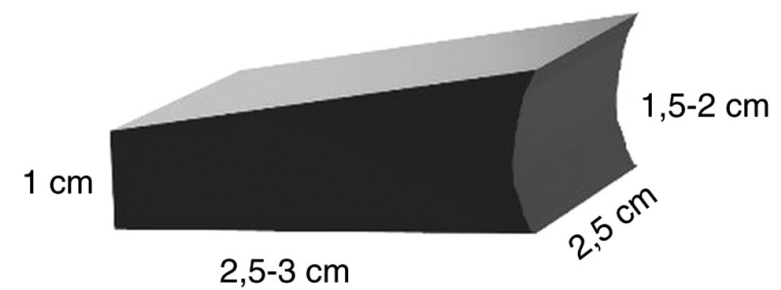

Figure 5. Average size that was used for iliac crest bone grafts. A 3D model with an anti-sliding design was constructed.

in vivo conditions, can influence the degradation time and biological response of the body concerning the implant. Yang et al used the Dmol3 calculation method (44) for determining the stability of four second-phase $\mathrm{Mg}-\mathrm{Ca}, \mathrm{Mg}-\mathrm{Sr}$, $\mathrm{Mg}-\mathrm{Zn}-\mathrm{Zr}, \mathrm{Mg}-\mathrm{Al}-\mathrm{Zn}$ alloys, these having higher phase stability than the $\mathrm{Mg}$ matrix. In the $\mathrm{Mg}-\mathrm{Al}-\mathrm{Zn}$ alloy, the $\mathrm{Mg}_{17} \mathrm{Al}_{12}$ second phase had good cytocompatibility in vitro and did not induce hemolysis (42).

Also, not all alloys form second phase particles. For example, in high quantities, Yttrium does not form second-phase particles due to the high solid solubility in $\mathrm{Mg}$, thus presenting under the form of solid solutions and achieving solid solution strengthening (41-43). This solid solution strengthening affects also the degradation of the $\mathrm{Mg}$ alloys improving the corrosion rate because of reducing the internal galvanic corrosion between the second phase and $\mathrm{Mg}$ matrix (45).

One important aspect in designing and proposing this $\mathrm{Mg}$ alloy for medical use, is the problem of impurities. During casting, impurities are introduced in the alloy, especially iron, nickel and copper. They can influence the corrosion characteristics of the product and can also be toxic for the human body. For example, nickel is extremely toxic for the human body. Copper has a high toxicity on the cell membrane. Therefore, when casting, molds without such elements should be used $(21,46,47)$.

Since a surgical approach to the calcaneus is prone to skin complications and sometimes sepsis, antibiotic prophylaxis should always be used. Vancomycin 1-1.5 g, one dose, $2 \mathrm{~h}$ before surgery is recommend. After surgery, the lower limb should be rested at a higher body level, in a fiber cast. Ice should be applied daily to prevent hematoma (48).

Data in literature regarding any bond between $\mathrm{Mg}$ implants and hematoma could not be found, but attention should also be paid to the prevention of infections.

The goal of the present study was to determine a close to perfect site location for artificial metal grafts. Since the iliac crest is a markedly favorable graft, being used in extremely complicated diseases and it exists in limited quantity, it is considered that the novelty of using large magnesium alloy implants is beneficial (11).

In conclusion, artificial materials are the future in medicine replacing the body-limiting grafting capabilities. They are safe and incur less comorbidities (49). This method could pave the way in reducing the discomfort and increasing the satisfaction of patients. Although further testing is required, this research represents a great starting point (50).

Numerous aspects have to be refined until this solution can be widely used. Our goal is not only patient satisfaction, 
Table I. Mechanical properties of test prototypes and bone.

\begin{tabular}{lccc}
\hline Tissue & Tensile strength $(\mathrm{MPa})$ & Young's modulus $(\mathrm{GPa})$ & Density $\left(\mathrm{g} / \mathrm{cm}^{3}\right)$ \\
\hline Cortical Bone & $35-280$ & $5-22$ & $1.8-2.0$ \\
Cancellous Bone & $1-40$ & $0.01-1.58$ & $1.0-1.4$ \\
Pure Mg & 90 & 44 & 1.74 \\
MgYREZr & $250-280$ & $44-46$ & 1.84 \\
Mg1Ca & $75-240$ & - & 1.73 \\
Ti6Al4V & $895-930$ & $110-114$ & 4.43 \\
\hline
\end{tabular}

but also the decrease of hospital charges and markedly faster rehabilitation. Patients can go back to work faster, in theory, without extra risks associated. Another problem that is often encountered is that a great number of patients are not in favor of the bone grafting therapeutic option. A fixation for this type of injury, without grafting is less stable and more prone to failure and dissatisfaction $(1,3,5)$. Using an $\mathrm{Mg}$ alloy graft assists this issue and appears to be a safe 'fix'.

In addition, in the case of failure, there is always the option of second-stage bone grafting or talo-calcaneal arthrodesis (51).

It is considered that the future of $\mathrm{Mg}$ alloys in orthopedics and in general medicine is certain, but more studies are required, for refining and testing and multi-disciplinary teams should work together to discover and demonstrate the best options.

The present study represents a starting point, by finding a favorable biological site for $\mathrm{Mg}$ grafts. A suitable $\mathrm{Mg}$ alloy was revealed, appropriate for our strategy. The present study is not an ending, but a beginning.

\section{Acknowledgements}

Professional editing, linguistic and technical assistance was performed by Irina Radu, Individual Service Provider, certified translator in Medicine and Pharmacy (certificate credentials: Series E no. 0048).

\section{Funding}

No funding was received.

\section{Availability of data and materials}

All data generated or analyzed during this study are included in this published article.

\section{Author's contributions}

SD planned the clinical study, contributed to the conception and design of the study, and the acquisition, analysis and interpretation of the data. DCC contributed to the analysis and interpretation of the data and the critical revision for important intellectual content. CDMD contributed to the conception and design of the study, analysis of data, the drafting of the manuscript and its critical revision for important intellectual content. CS contributed to the conception and design of the study and the critical revision of the manuscript for important intellectual content. CIS contributed to the conception and design of the study, the interpretation of the data and the critical revision of the manuscript for important intellectual content. All authors read and approved the final version of the manuscript and agree to be accountable for all aspects of the study.

\section{Ethics approval and consent to participate}

The study on the one mouse used was approved by the Ethics Committee from the Faculty of Veterinary Medicine in Bucharest (Bucharest, Romania) with respect to the current legislation regarding the protection of laboratory animals.

\section{Patient consent for publication}

Not applicable.

\section{Competing interests}

The authors declare that they have no competing interests.

\section{References}

1. Schepers T, van Lieshout EM, van Ginhoven TM, Heetveld MJ and Patka P: Current concepts in the treatment of intra-articular calcaneal fractures: Results of a nationwide survey. Int Orthop 32: 711-715, 2008.

2. Atkins RM, Allen PE and Livingstone JA: Demographic features of intra-articular fractures of the calcaneum. Foot Ankle Surg 7: 77-84, 2001.

3. Soeur R and Remy R: Fractures of the calcaneus with displacement of the thalamic portion. J Bone Joint Surg Br 57: 413-421, 1975.

4. Slatis P, Kiviluoto O, Santavirta S and Laasonen EM: Fractures of the calcaneum. J Trauma 19: 939-943, 1979.

5. Buckley R, Tough S, McCormack R, Pate G, Leighton R, Petrie D and Galpin R: Operative compared with nonoperative treatment of displaced intra-articular calcaneal fractures: A prospective, randomized, controlled multicenter trial. J Bone Joint Surg Am 84: 1733-1744, 2002.

6. Essex-Lopresti P: The mechanism, reduction technique, and results in fractures of the os calcis. Br J Surg 39: 395-419, 1952.

7. Rak V, Ira D and Masek M: Operative treatment of intra-articular calcaneal fractures with calcaneal plates and its complications. Indian J Orthop 43: 271-280, 2009.

8. Bajammal S, Tornetta P III, Sanders D and Bhandari M: Displaced intra-articular calcaneal fractures. J Orthop Trauma 19: 360-364, 2005.

9. Brauer CA, Manns BJ, Ko M, Donaldson C and Buckley R: An economic evaluation of operative compared with nonoperative management of displaced intra-articular calcaneal fractures. J Bone Joint Surg Am 87: 2741-2749, 2005.

10. Pozo JL, Kirwan EO and Jackson AM: The long-term results of conservative management of severely displaced fractures of the calcaneus. J Bone Joint Surg Br 66: 386-390, 1984. 
11. Stark JG: Use of selective estrogen receptor modulator for joint fusion and other healing of connective tissue. US Patent 8,501,690 B2, Filed April 30, 2010; issued August 6, 2013.

12. Liu C, Wan P, Tan LL, Wang K and Yang K: Preclinical investigation of an innovative magnesium-based bone graft substitute for potential orthopaedic applications. J Orthop Translat 2: 139-148, 2014.

13. Calori GM, Mazza E, Colombo M and Ripamonti C: The use of bone-graft substitutes in large bone defects: Any specific needs? Injury 42 (Suppl 2): S56-S63, 2011.

14. Van der Stok J, Van Lieshout EM, El-Massoudi Y, Van Kralingen GH and Patka P: Bone substitutes in the Netherlands-a systematic literature review. Acta Biomater 7 : 739-750, 2011

15. Almaiman M, Al-Bargi HH and Manson P: Complication of anterior iliac bone graft harvesting in 372 adult patients from May 2006 to May 2011 and a literature review. Craniomaxillofac Trauma Reconstr 6: 257-266, 2013.

16. Böstman $\mathrm{O}$ and Pihlajamäki H: Clinical biocompatibility of biodegradable orthopaedic implants for internal fixation: A review. Biomaterials 21: 2615-2621, 2000.

17. AuerJA, Rechenberg BV,BohnerMandHofmann-Amtenbrink M: Bone grafts and bone replacements. Equine Surg 2012: 1081-1096, 2012

18. Dias AG, Lopes MA, Gibson IR and Santos JD: In vitro degradation studies of calcium phosphate glass ceramics prepared by controlled crystallization. J Non Cryst Solids 330: 81-89, 2003.

19. Kim HM: Ceramic bioactivity and related biomimetic strategy. Curr Opin Solid State Materials Sci 7: 289-299, 2003.

20. Giannoudis PV, Dinopoulos H and Tsiridis E: Bone substitutes: An update. Injury 36 (Suppl 3): S20-S27, 2005.

21. Waizy H, Seitz JM, Reifenrath J, Weizbauer A, Bach FW, Meyer-Lindenberg A, Denkena B and Windhagen H: Biodegradable magnesium implants for orthopedic applications. J Mater Sci 48 : 39-50, 2013

22. Seal CK, Vince K and Hodgson MA: Biodegradable surgical implants based on magnesium alloys-A review of current research. IOP Conf Ser: Mater Sci Eng: 4, 2009.

23. Su Y, Chen W, Zhang T, Wu X, Wu Z and Zhang Y: Bohler's angle's role in assessing the injury severity and functional outcome of internal fixation for displaced intra-articular calcaneal fractures: A retrospective study. BMC Surg 13: 40, 2013.

24. Sanders R, Fortin P, DiPasquale T and Walling A: Operative treatment in 120 displaced in-traarticular calcaneal fractures. Results using a prognostic computed Tomogra-phy scan classification. Clin Orthop Relat Res 290: 87-95, 1993.

25. Kuhlmann J, Bartsch I, Willbold E, Schuchardt S, Holz O, Hort N, Höche D, Heineman WR and Witte F: Fast escape of hydrogen from gas cavities around corroding magnesium implants. Acta Biomaterialia 9: 8714-8721, 2013.

26. Lukyanova E, Yu N, Yu AN, Martynenko AN, Martynenko N and Estrin Y: Features of in vitro and in vivo behaviour of magnesium alloy WE43. Materials Lett 215: 308-311, 2018.

27. Xiaoting S, Yuanyuan Z, Shufang Z, Rongfang Z, Rongfa Z, Chen L and Yijia Z: Characteristics of selenium-containing coatings on WE43 magnesium alloy by micro-arc oxidation. Mater Lett 261: 126944, 2020.

28. Rahim MI, Ullah S and Mueller PP: Advances and challenges of biodegradable implant materials with a focus on magnesium-alloys and bacterial infections. Metals 8: 532, 2018

29. Ding Y, Wen C, Hodgson P and Li Y: Effects of alloying elements on the corrosion behavior and biocompatibility of biodegradable magnesium alloys: A review. J Mater Chem B 2: 1912-1933, 2014.

30. Wang $\mathrm{H}$ and Shi $\mathrm{Z}$ : In vitro biodegradation behavior of magnesium and magnesium alloy. J Biomed Mater Res Part B Appl Biomater 98: 203-209, 2011.

31. Song Y, Shan D, Chen R, Zhang F and Han EH: Biodegradable behaviors of AZ31 magnesium alloy in simulated body fluid. Mater Sci Eng C 29: 1039-1045, 2009.

32. Yan T, Tan L, Xiong D, Liu X, Zhang B and Yang K: Fluoride treatment and in vitro corrosion behavior of an AZ31B magnesium alloy. Mater Sci Eng C 30: 740-748, 2010.
33. Witte F, Fischer J, Nellesen J, Crostack HA, Kaese V, Pisch A, Beckmann $\mathrm{F}$ and Windhagen $\mathrm{H}$ : In vitro and in vivo corrosion measurements of magnesium alloys. Biomaterials 27: 1013-1018, 2006.

34. Witte F, Kaese V, Haferkamp H, Switzer E, Meyer-Lindenberg A, Wirth CJ and Windhagen $\mathrm{H}$ : In vivo corrosion of four magnesium alloys and the associated bone response. Biomaterials 26 $3557-3563,2005$

35. Tan L, Yu X, Wan P and Yang K: Biodegradable materials for bone repairs: A review. J Mater Sci Technol 29: 503-513, 2013.

36. Hong D, Saha P, Chou DT, Lee B, Collins BE, Tan Z, Dong Z and Kumta PN: In vitro degradation and cytotoxicity response of $\mathrm{Mg}-4 \% \mathrm{Zn}-0.5 \% \mathrm{Zr}$ (ZK40) alloy as a potential biodegradable material. Acta Biomater 9: 8534-8547, 2013.

37. Gu XN, Li N, Zheng YF and Ruan L: In vitro degradation performance and biological response of a $\mathrm{Mg}-\mathrm{Zn}-\mathrm{Zr}$ alloy. Mater Sci Eng B 176: 1778-1784, 2011.

38. Li Z, Gu X, Lou S and Zheng Y: The development of binary $\mathrm{Mg}-\mathrm{Ca}$ alloys for use as biodegradable materials within bone. Biomaterials 29: 1329-1344, 2008.

39. Zhao C,Pan F, Zhang L,Pan H, Song K and Tang A: Microstructure, mechanical properties, bio-corrosion properties and cytotoxicity of as-extruded $\mathrm{Mg}$-Sr alloys. Mater Sci Eng C Mater Biol Appl 70: 1081-1088, 2017.

40. Kannan MB: Influence of microstructure on the in-vitro degradation behaviour of magnesium alloys. Mater Lett 64: 739-742, 2010.

41. Zhang S, Zhang X, Zhao C, Li J, Song Y, Xie C, Tao H, Zhang Y, He Y, Jiang Y and Bian Y: Research on an Mg-Zn alloy as a degradable biomaterial. Acta Biomater 6: 626-640, 2010.

42. Liu C, He P, Wan P, Li M, Wang K, Tan L, Zhang Y and Yang K: The in vitro biocompatibility and macrophage phagocytosis of Mg17Al12 phase in Mg-Al-Zn alloys. J Biomed Mater Res A 103: 2405-2415, 2015

43. Gao L, Chen RS and Han EH: Solid solution strengthening behaviors in binary Mg-Y single phase alloys. J Alloys Compd 472: 234-240, 2009.

44. Yang H, Liu C, Wan P, Tan L and Yang K: Study of second phase in bioabsorbable magnesium alloys: Phase stability evaluation via Dmol ${ }^{3}$ calculation. APL Materials: Nov 8, 2013 (Epub ahead of print) doi: org/10.1063/1.4828935.

45. Zhang X, Zhang K, Li X, Deng X, LI Y, Ma M and Shi Y: Effect of solid-solution treatment on corrosion and electrochemical behaviors of $\mathrm{Mg}-15 \mathrm{Y}$ alloy in 3.5 wt.\% $\mathrm{NaCl}$ solution. J Rare Earths 30: 1158-1167, 2012

46. Südholz AD, Kirkland NT, Buchheit RG and Birbilis N: Electrochemical properties of intermetallic phases and common impurity elements in magnesium alloys. Electrochem Solid St Lett 14: C57, 2011

47. Hofstetter J, Martinelli E, Pogatscher S, Schmutz P, PovodenKaradeniz E, Weinberg AM, Uggowitzer PJ and Löffler JF: Influence of trace impurities on the in vitro and in vivo degradation of biodegradable $\mathrm{Mg}-5 \mathrm{Zn}-0.3 \mathrm{Ca}$ alloys. Acta Biomater 23: $347-353,2015$.

48. Crawford T, Rodvold KA and Solomkin JS: Vancomycin for surgical prophylaxis? Clin Infect Dis 54: 1474-1479, 2012

49. Chen L, Peng W, Li LT, Kehong W and Ke Y: Preclinical investigation of an innovative magnesium-based bone graft substitute for potential orthopaedic applications. J Orthop Translat 2: 139-148, 2014.

50. Sommar P, Granberg Y, Halle M, Skogh AC, Lundgren KT and Jansson KA: Effects of a formalized collaboration between plastic and orthopedic surgeons in severe extremity trauma patients; a retrospective study. J Trauma Manag Outcomes 9: 3 , 2015.

51. Buch BD, Myerson MS and Miller SD: Primary subtalar arthrodesis for the treatment of comminuted calcaneal fractures. Foot Ankle Int 17: 61-70, 1996.

This work is licensed under a Creative Commons Attribution-NonCommercial-NoDerivatives 4.0 International (CC BY-NC-ND 4.0) License. 